KINETIK, Vol. 3, No. 2, May 2018, Pp. 135-144

ISSN :2503-2259

E-ISSN : 2503-2267

135

\title{
Monitoring Fuel Oil Based on Radio Frequency Identification (RFID) Client
}

\author{
Dezar Septiantono*1, Zulfatman², Budhi priyanto ${ }^{3}$ \\ 1,2,3 Universitas Muhammadiyah Malang \\ dezarseptian12@gmail.com¹, zulfatman78@umm.ac.id², budhi@umm.ac.id ${ }^{3}$
}

\begin{abstract}
Motorcycles are a means of transportation which plays an important role in people's lives. One of the existing problems on the motorcycle is the indicator system or often called by speedometer, an indicator system showing the value of the volume of fuel oil. In fact, the sensor unit used by the indicator is not a volume sensor but the surface of the fuel sensor in the form of mechanical potentiometers. This equipment irregularly measures oil tank so that the mathematical approach to formulate the relationship between surface height and gasoline volume will be difficult. Therefore, to interpret the data manipulation done by comparison method is the method of comparison experiment and calculation. This method is applied in this research due its more superior accuracy and efficiency. This research designs hardware for monitoring fuel oil based on Radio Frequency Identification (RFID) using AT mega 328 as main controller and $L C D$ to display driver's identity sent by General Packet Radio Service (GPRS). The sensor used is a buoy sensor, measuring the fuel volume between 0.20 liters to 9.55 liters. It is known that the comparative method has an average rate of $16.1 \%$, in measuring the fuel volume between 0.20 liters to 3.68 liters. It is known that the comparative method has an average rate of $17.9 \%$. On measuring the fuel volume between 0.20 liters to 3.43 liters, the comparative method having an average rate of $7.2 \%$ is employed. Based on the test results, the best comparison method in comparison with the interpolation method with the average rate of smallest $7.2 \%$ is determined.
\end{abstract}

Keywords: RFID, LCD, GPRS, Mikrokontroler ATmega 328

\section{Introduction}

The increasing number of motorcycle vehicles leads to the demand for fuel oil, so an efficient and efficient tool is needed to monitor the fuel oil to effectively save gas money and broken engine.

General Packet Radio Service (GPRS) is a wireless communication technology that can transmit data over the internet. The characteristics possessed by Global Positioning System (GPS) and GPRS can be integrated to build vehicle tracking systems [1]. In this project, the researcher uses GPS Tracker, being very useful to give the information signal of the parked vehicle location and while in mobile. With the monitoring tool, we can be more thorough to monitor the system utilizing Google Maps. In the case of any car stealing, the current location of the stolen vehicle can be easily monitored [1].

The design of gasoline volume measurement using interpolation method based on 8535 Microcontroller [2] has been previously studied by Aziz [2]. Aziz testing using interpolation method can measure the height level of the sensor volume between $5.959377 \%$ to $8.590511 \%$ as well as the volume measurement between 0.8 liters to 2.3 liters [2].

This research entitiled "Monitoring Radio Based Fuel Frequency IDentification (RFID)".offers assistance for vehicle owners to monitor fuel consumption in real time here the writing makes a final task related to it, with the theme and title "Monitoring Fuel Oil Based on Radio Frequency IDentification (RFID)".

\section{Research Method}

\subsection{Block diagram}

Radio frequency monitoring system based on radio frequency identification presented by Figure 1 is employing ATmega 328. ATmega system serves as the main control. 
Figure 1 illustrates the part governing radio frequency identification. The sensor itself serves to detect the volume of fuel oil while the global positioning system-based modem functions to provide information related to our position coordinates. Therefore, radio frequency identification is able to receive and process data obtained from the sensor.

Section database is a sub system, being useful as a data storage received from radio frequency identification. The data from radio frequency identification is transmitted with a specified time interval to a specific IP address, MySQL user name and password [3].

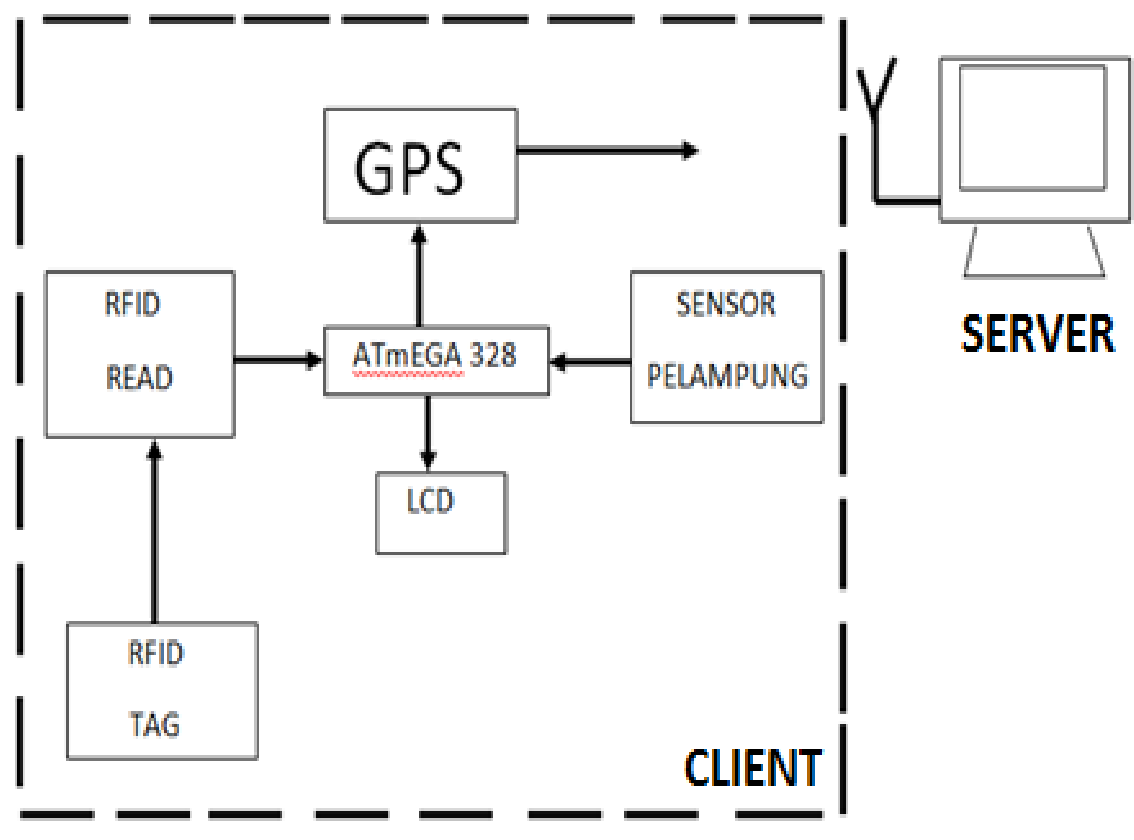

Figure 1. General Diagram of System Monitoring Between Client-Server

\subsection{Flowchart}

The device design of a radio frequency identification (RFID) based fuel monitoring system is illustrated in the previously given flowchart. The algorithm flow of the system in the form of a flowchart is presented in Figure 2.

Moreover, Figure 2 describes the system design. Initially, entering identity data to the radio frequency identification and ATmega 328 system, automatically reading this data, becomes the initial process. Afterwards, IDM will process this information by the identity 328 . The results can be accessed by the scanning process from ID Card previously programmed. Once the sensor is activated, it will perform its task in the command by the program. The data, utilizing sensor, will be analyzed, automatically stored and displayed on the screen Liquid Crystal Display (LCD) utilizing

\subsection{Mechanical Design}

The mechanical design consists of the first three sections. The first part is the electronics circuit. The second part is applied inside the motorcycle tank. The third part is a gallon as a container.

Figure 3 above shows a general overview of mechanical design that has been connected to the minimum system, a buoy sensor used to measure the volume of fuel in the tank and a gallon used to accommodate fuel oil flowing from the tank. Therefore, the buoy sensor will continue to provide fuel volume information in real time.

\subsection{ATmega 328 Microcontroller}

ATMega 328 is an output microcontroller from ATmel which has a Reduce Instruction Set Computer architecture having faster data execution process than Completed Instruction Set Computer [4]. 
2.5 Designing Arduino Uno using Liquid Crystal Display (LCD) 16 X 2

Liquid Crystal Display (LCD) is a media type viewer [5] as the main viewer shown in Figure 4. Figure 5 presents diagram testing program Arduino uno with LCD libraray I2C as LCD address with value of $0 \times 27,2,1,0,4,5,6,7,4$ and 3 positives, then the LCD address will be recognized. The LCD size is $16 \times 2$ with 0 column 0 line on LCD and is displayed at 1 second.

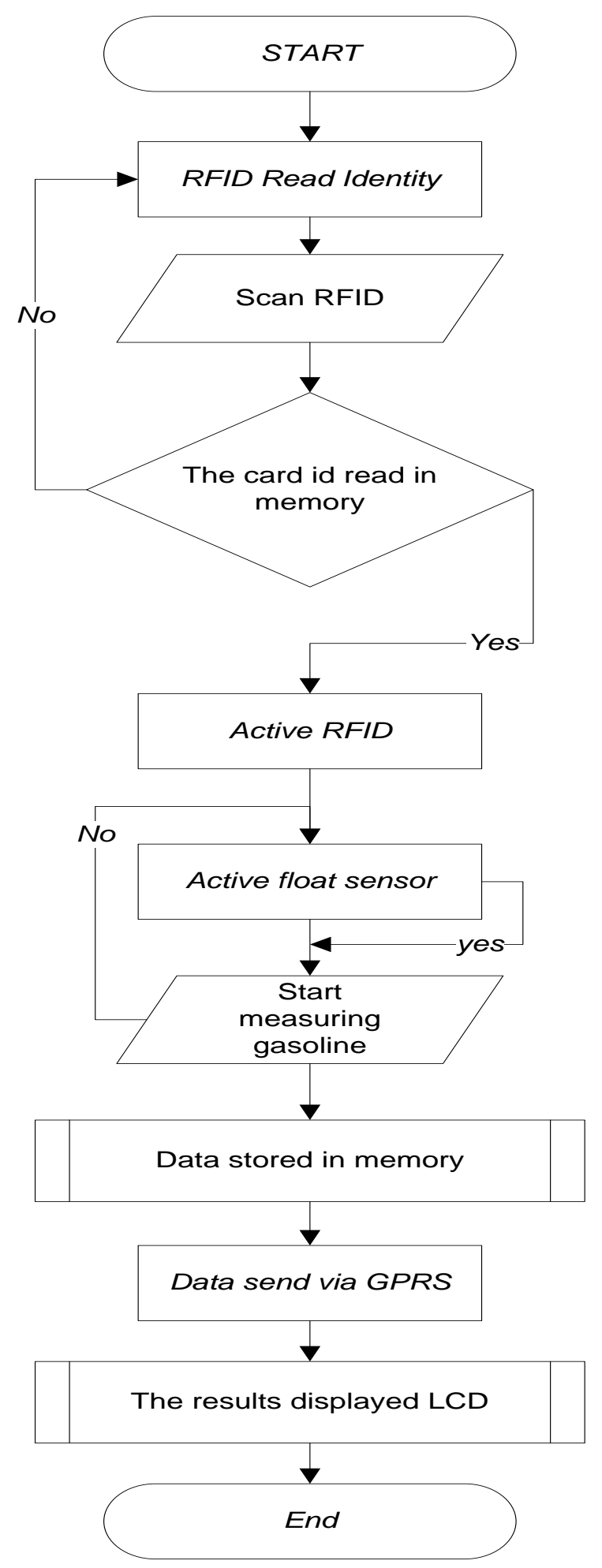

Figure 2. Flowchart of Client System Design 


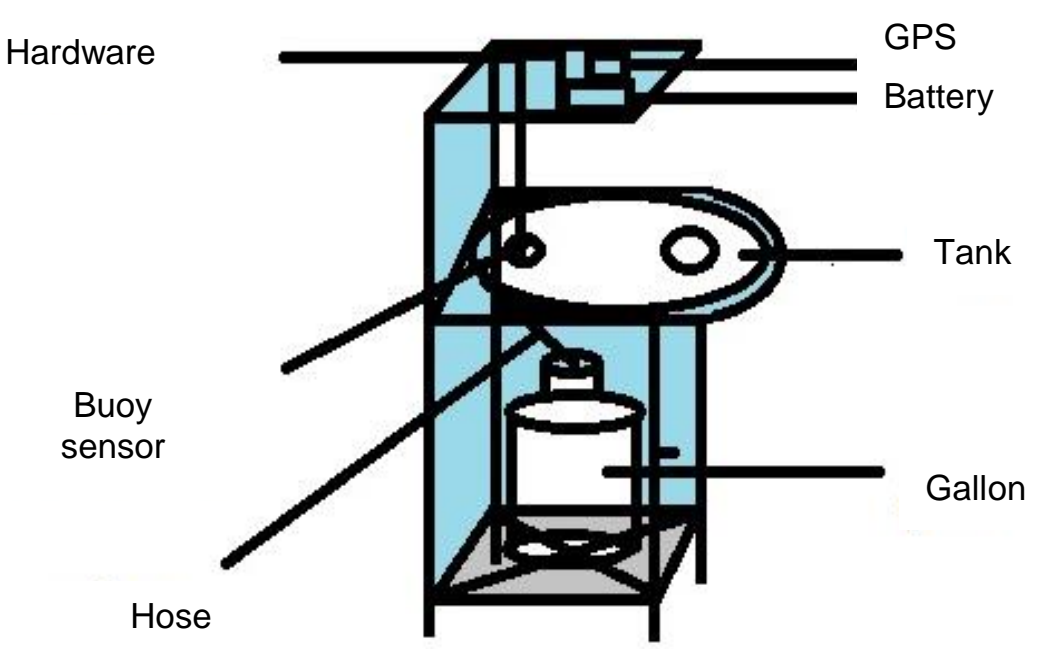

Figure 3. Tool Design (Prototype)



Figure 4. Liquid Crystal Display [6].

Besides the LCD can also be used to display characters or images [7].

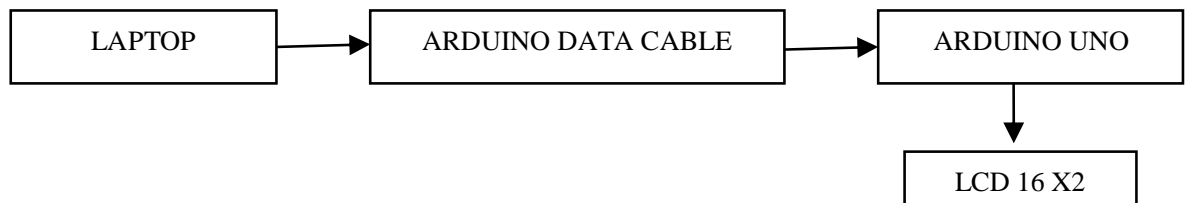

Figure 5. Block Diagram of Arduino Uno Scale with LCD

\subsection{Arduino uno design with RFID}

Active RFID tags are used for asset goods, every cargo ship or postal document which requires both remote and close tracking between $455 \mathrm{Mhz}$ up to $2.45 \mathrm{GHz}$ and a distance of 60 300 feet equivalent to 100 meters [8]. In addition to RFID, it may also be written and read repeatedly [9]. RFID chip is presented in Figure 6.

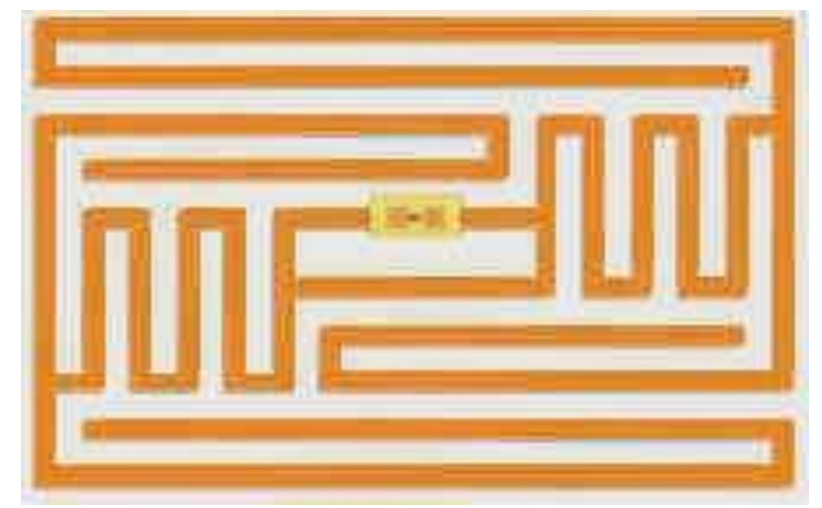

Figure 6. Example of RFID Chip [10]. 
To determine whether the RFID reader circuit that has been made to work as desired, RFID reader circuit is tested by connecting with the minimum system of Arduino Uno R3. RFID working system is shown in Figure 7.

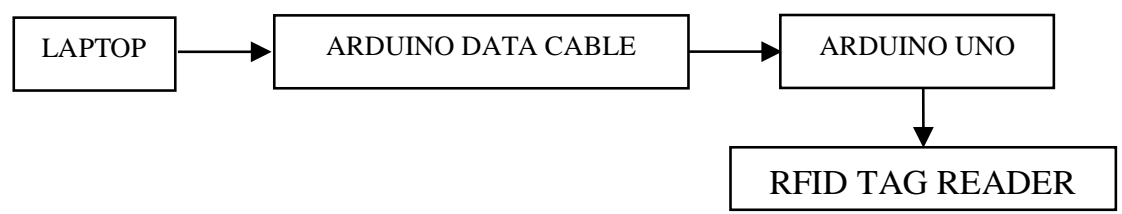

Figure 7. Block diagram of Arduino Uno with RFID

Figure 7 illustrates Arduino Uno program testing diagram with RFID utilizing RFID card and reader program. The RFID card will be valued 0 if card 0 even though RFID takes four input data and will be in quantity when checking RFID card. When the checking process is completed, RFID will stop to give the received output on the card 1 showing Paijo (as an example driver); afterwards, the card shows Paijo in 3 seconds.

\subsection{Arduino Uno design with GPS}

GPS Tracker or GPS Tracking is one of the tools to detect the existence and speed of any designated vehicles such as cars [6], motors, trucks or any detected vehicles through sms media or digital map. The GPS working system is shown in Figure 8.



Figure 8. Test Block Diagram of Arduino Uno with GPS

Figure 8 illustrates the diagram testing program of Arduino Uno with GPS explaining the GPS program which will provide information when the vehicle is running while getting the GPS signa. It will search of any latitude and longitude even though GPS takes long-distance data in 10 second interval.

\subsection{Design of Arduino Uno GPRS}

GPRS can be used to send data to the server through a website. Sim $800 \mathrm{~L}$ is one GSM or GPRS serial modules which can be used with Arduino and AVR. There are several types of breakout board of Sim 800L and Sim 800 . However, this research will employ and discuss Sim $800 \mathrm{~L}$ [10]. The GPS circuit of this test reads the information in the form of the location coordinate point. To find out whether GPS circuit which has been created can work as desired, a GPS circuit test is connected with the minimum Arduino Uno R3 system. The following Figure 9 presents working system Arduino Uno test with GPRS.

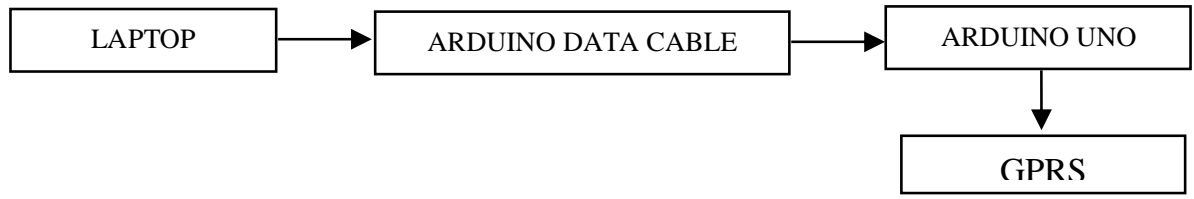

Figure 9. Arduino Uno Test Diagram Block with GPRS

Figure 9 explains the test diagram of Arduino Uno program with GPRS. GPRS program will receive print from Arduino Uno to upload data update to server within 10 seconds. When vehicle running GPRS get data from GPS, it will show latitude and longitude on server which have been sent by GPRS.

\subsection{Design of Arduino Uno with Buoy Sensor}

The buoy sensor is a sensor serving to provide fuel oil information on motorcycles and cars [11]. Figure 10 illustrates the sensor working system. 


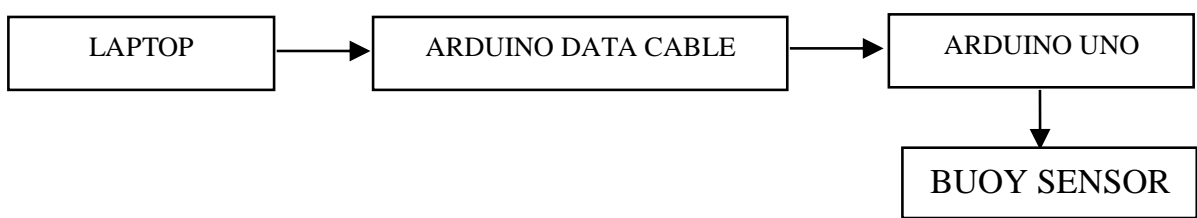

Figure 10. Test Block Diagram of Arduino Uno with Buoy Sensor

According to Figure 10, readings can be conducted by installing a sensor with a position which has been suggested for example on the tank of the motor. This method is quite well applied to motor tanks considered to have low height level of positioning [11]. The test conducted in the block diagram explaines when the Arduino Uno gives command then the buoy sensor will measure the volume of gasoline in the motor tank. The "full tank" information will be displayed on the LCD by displaying as $100 \%$.

\section{Research Results and Discussion}

After the stages of software development have been completed, the following step is testing the system created. This test determines the measurement results of the fuel oil.

\subsection{Tool Implementation}

Designing tool is conducted in this stage. Each module is installed and arranged in accordance with the sockets of the hardware used to be able to monitor fuel based radio frequency identification.

Figure 11 is an installation process of a hardware set which will be used to connect a floating sensor circuit.

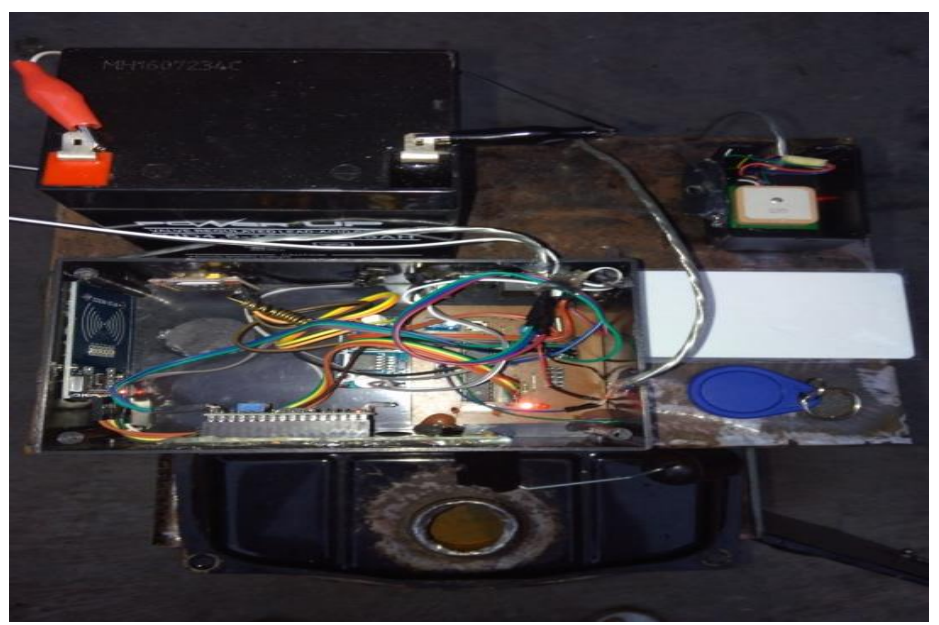

Figure 11. Installation of Top Viewer

\subsection{System Test Results}

The results of testing the system for both hardware and software systems will be discussed at this stage. Components which have been integrated will be tested as a whole to ensure the system is running properly. The test results performed at this stage include:
1. Arduino Uno test results with $16 \times 2$ LCD.
2. Arduino Uno test results with RFID.
3. Arduino Uno test results with GPS.
4. Arduino Uno test results with GPRS.
5. Arduino Uno test results with buoy sensor.

\subsubsection{Arduino Uno Test Results with 16x2 LCD}

The result of testing of LCD $16 \times 2$ is obtained at this stage after all necessary tools are installed and connected. According to the testing result, the test results this stage shows active program of LCD command displaying STARTING staatus. 




Figure 12. LCD Test Results

Figure 12 presents the Arduino Uno test results displayed on LCD. At the time, LCD is given Icd.print ("starting"); consecutively, LCD will display STARTING indicating that LCD is active in 1 second duration with command delay of 1000 .

\subsubsection{Arduino Uno Test Results with RFID}

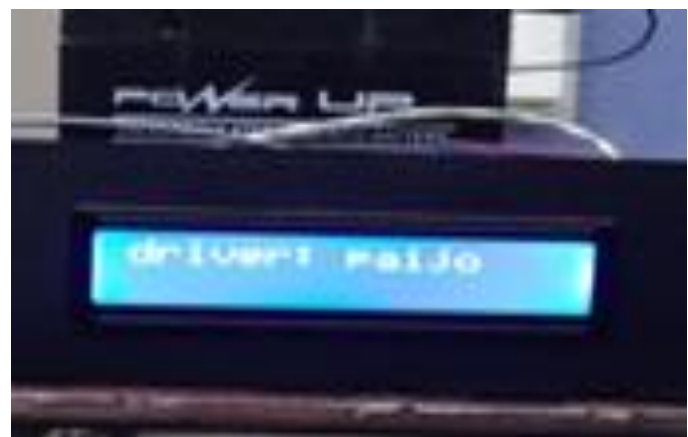

Figure 13. Test Results of RFID Reader and Taq RFID

When LCD is given the command \#include <Wire.h $>$ which is the library of the LCD, LCD will display the character indicating LCD is well figured. In addition, in order to remove unwanted characters, Icd.clear () command is written. Furthermore, LCD will display the identity name of the driver as shown in Figure 13 by writing command (card == card1) \{driver = "paijo"; Icd.print (driver); with card logic equal to one displaying the driver's named PAIJO. However, using the command (card == card2 \{driver = "bejan"; Icd.print (driver); $\}$ with card logic equal to two, LCD will display a driver named BEJAN with command delay of 3000 , with 3 seconds to respond to Taq RFID card.

\subsubsection{Arduino Uno Test Results with GPS}

In the main LCD display, there are 3 test results displayed on the LCD, coordinate map, fuel oil (BBM) and speed (RPM).

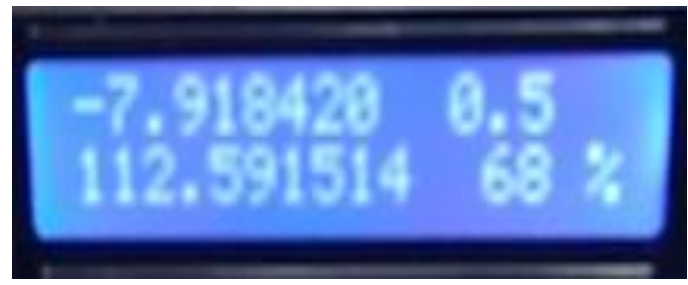

Figure 14. GPS Test Results

As illustrated in Figure 14, the Arduino Uno test results on GPS can be displayed. GPS is given command \#include <SoftwareSerial.h> for serial communication to GPS and command \#include <TinyGPS.h> for GPS library. Meanwhile, TinyGPS GPS is the name of the GPS library to give command for software serial 3 and 4 to determine RX TX pin on GPS. The static void smart delay (unsigned long $\mathrm{ms}$ ) is the delay to receive GPS data. Using float command, the data from GPS library will be able to be obtained. Then time command will be given by data unsigned long age, date, time, chars $=0$, and when failing with command unsigned short sentences $=0$, failed $=0$. After all completed, then it will be given a command that will be directly connected to the GPS center that is static const double LONDON_LAT $=51.508131$, LONDON_LON $=-0.128002$. The data speed can be obtained with the command float lat, lon, speed. 




Figure 15. General Test Result on Google Maps

As presented in Figure 15, the GPS test results on Google Maps can be achieved utilizing GPS in Google Maps which is provided by Google. The command can be entered if necessary. When in need to track movement, it can be presented from the marked traces of the vehicle's recorded locations. The red trail is a real time position performed during the test taking place with 10 seconds update in hardware monitoring. At the time while tracking, the report on the journey showing in the update and some other reports such as date, time, speed (Rpm), fuel oil conditions, latitude and longitude can also be obtained.

\subsubsection{Arduino Uno Test Results with GPRS}

Figure 16 presents Arduino Uno test results on GPS. When GPRS is given void command SubmitHttpRequest (), it will command upload web data, before uploading web data then the signal quality with Serial.command ("AT + CSQ") will be checked using ShowSerialData (). After having a good signal then we will check whether GPRS support or not with In Serial. Print command ("AT + CGATT?"); delay (100); delayed time of 1 second.

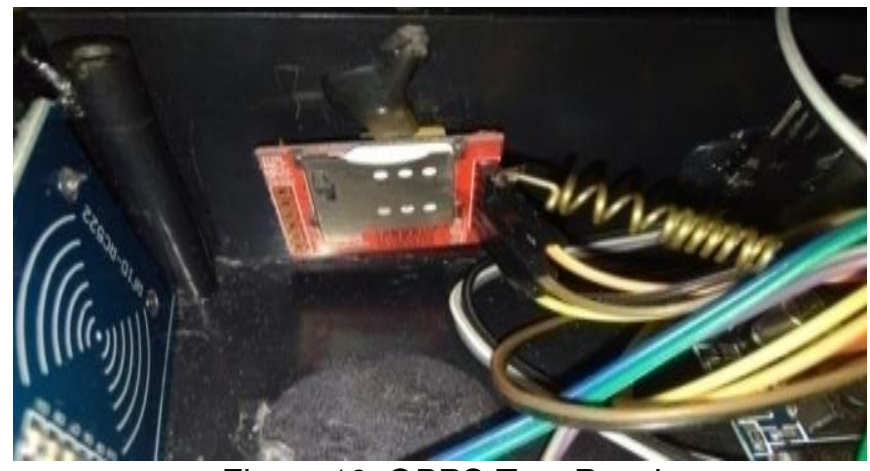

Figure 16. GPRS Test Result

Table 1. Results of Data Delivery from GPRS SIM800L to Server

\begin{tabular}{ccccccc}
\hline No & Date & Time & Speed & BBM & Latitude & Longitude \\
\hline 1 & $31 / 7 / 2017$ & $14: 06: 20$ & 0.78 & $31 \%$ & -7.921139 & 112.632713 \\
2 & $31 / 7 / 2017$ & $14: 04: 58$ & 9.87 & $76 \%$ & $-7,921,184$ & 112.632289 \\
3 & $31 / 7 / 2017$ & $14: 04: 35$ & 4.35 & $52 \%$ & -7.921538 & 112.632873 \\
4 & $31 / 7 / 2017$ & $14: 04: 13$ & 13.72 & $77 \%$ & -7.922065 & 112.633255 \\
5 & $31 / 7 / 2017$ & $14: 13: 51$ & 26.97 & $76 \%$ & -7.922781 & 112.633384 \\
6 & $31 / 7 / 2017$ & $14: 03: 29$ & 18.33 & $69 \%$ & -7.92348 & 112.63488 \\
7 & $31 / 7 / 2017$ & $14: 03: 07$ & 11.2 & $52 \%$ & -7.924109 & 112.635002 \\
8 & $31 / 7 / 2017$ & $14: 02: 45$ & 38.21 & $76 \%$ & -7.925167 & 112.634086 \\
9 & $31 / 7 / 2017$ & $14: 02: 24$ & 14.74 & $44 \%$ & -7.926554 & 112.633049 \\
10 & $31 / 7 / 2017$ & $14: 02: 02$ & 32.61 & $69 \%$ & -7.92821 & 112.633049
\end{tabular}

KINETIK Vol. 3, No. 2, May 2018: 135-144 
Table 1 presents the testing results of GPRS SIM $800 \mathrm{~L}$ data transmission. The results on delivery date of 31 July 2017 at 14:06:20 shows the motorcycle speed (RPM) of 0.78 with $31 \%$ fuel oil conditions. The position of the vehicle is located at latitude -7.921139 coordinate and longitude of 112.632713. On the same date at 14:04:13, it has different result with the speed of 13.72 (RPM) with the fuel condition of $77 \%$ because of some influences of unstable gasoline volume while riding on steep roads. The position of the vehicle is at the coordinates of latitude 7.922065 and longitude 112.633255

\subsubsection{Arduino Uno Test Result with Buoy Sensor}

As shown by Figure 17, the results of fuel oil decline can be deduced. At the moment, the buoy sensor is given the command bbm = map (analogread (A0), 35.490, 100.0); then the program will take the data of fuel oil (BBM) when there is a change monitored. This float sensor is significantly usefull playing as information on the fuel oil volume in the test equipment. To identify the tank volume to be displayed in the LCD, the command if $(\mathrm{bbm}>100)\{\mathrm{bbm}=100 ;\}$ is given to read fuel oil at position of 100 . If command $(\mathrm{bbm}>50)\{\mathrm{bbm}=50 ;\}$ is given, the sensor will read fuel oil position of 50 . By giving the command $(\mathrm{bbm}<0)\{\mathrm{bbm}=0 ;\}$, then less than 0 fuel oil at position 0 is received.

On the test of the buoy sensor, the results of data transmission are presented in Table 2. It shows the delivery result date of 31 July 2017 at 14:06:20 with the motorcycle speed (RPM) of 0.78 having $31 \%$ fuel oil condition. The position of the vehicle is located at latitude -7.921139 coordinate and longitude 112.632713. On the same date at 14:02:45, different result is obtained with the speed of 38.21 (RPM) with the fuel condition of $76 \%$ in because influenced by unstable gasoline volume from riding on the steep road. The position of the vehicle is at the coordinates of latitude -7.925167 and longitude 112.634086. On the same date at 14:04:13, it is obtained different results with the speed of 13.72 (RPM) having $77 \%$ fuel condition while climbing the road; therefore, experiencing unstable derivative gas volume. The position of the vehicle is at the coordinates of latitude -7.922065 and longitude 112.633255 .

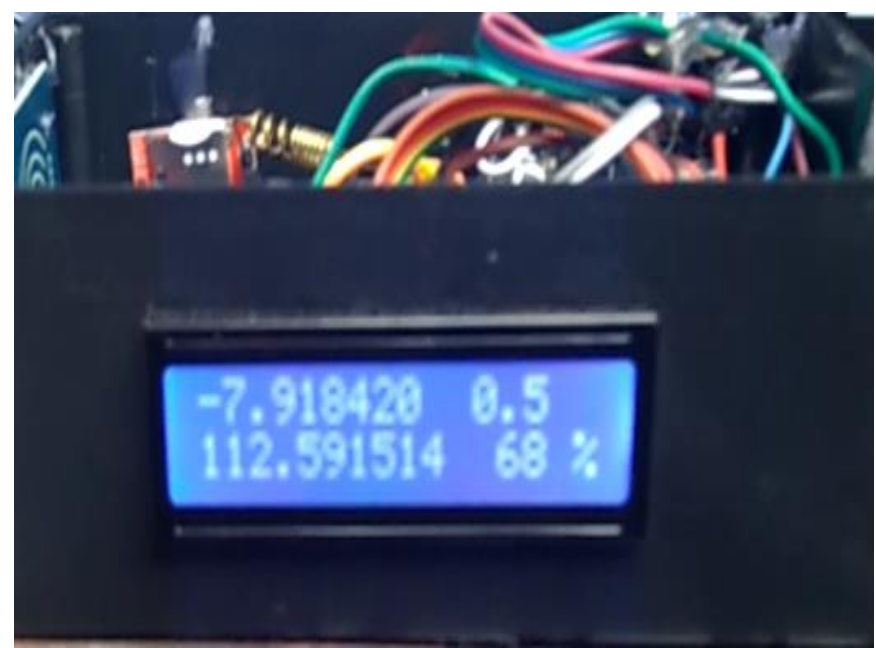

Figure 17. Result of oil fuel decrease showing $68 \%$.

Table 2. Result of oil fuel decrease report (server)

\begin{tabular}{ccc}
\hline BBM & LATITUDE & LONGITUDE \\
\hline 31 & -7.921139 & 112.632713 \\
76 & -7.921184 & 112.632289 \\
52 & -7.921538 & 112.632873 \\
77 & -7.922065 & 112.633255 \\
76 & -7.922781 & 112.633384 \\
69 & -7.92348 & 112.63488 \\
52 & -7.924109 & 112.635002 \\
76 & -7.925167 & 112.634086 \\
44 & -7.926554 & 112.633049 \\
69 & -7.92821 & 112.633049 \\
\hline
\end{tabular}

Monitoring Fuel Oil Based Radio Frequency Identification (RFID) Client. Kinetik Dezar Septiantono, Zulfatman, Budhi Priyanto 


\section{Conclusion}

Based on the discussion of the test results on the monitoring system of fuel oil based on Radio Frequency Identification (server), the results can be summed up as follows. The data update is conducted every 10 second, but according to testing results, there is an existing delay until reaching 22 seconds. This is because the Internet network becomes unstable, thus affecting the performance of data updates leading to delays. The height sensor used has a measurement error rate from $12.987013 \%$ to $32.2580645 \%$ with an average of $22.622539 \%$ on the volume measurement between 0.03 liters up to 0.18 liters. The GPS system will be effective at any distance, as long as it gets a good Internet network as well as a strong GPS signal quality. In order to obtain the protocol on the server, the users may perform HTTP request by entering trace.testing.com.

\section{Notations}

Examples of notations can be explained by the following description:

Lalitude : : Latitude -7.921139.

Longitude : : Line 112.632713.

BBM : Volume of fuel oil.

Time : Update Time.

\section{References}

[1] N. Hartatik, "Car Tracking Applications on Car Rental Information Systems," Eepis repos, Pp. 1-5, 2012.

[2] A. Aziz and T. Andromeda, "Paper of Final Design of Gasoline Volume Measurement Using ATMEG8535 Microcontroller Based Interpolation Method," Pp. 1-9, 2015.

[3] S. Susanti, "Prototype of Student Monitoring System Using RFID Technology (Radio Frequency Identification) and Sms Gateway Based Client Server (Case Study: SMA Saint Paul Pontianak)," Pp. 1-6, 2014.

[4] A. Muzani, R. Praeko, and A. Setiawan, "Design of Digital Penetrometer Based on Microcontroller Atmega 8535, "Faculty of Agricultural Technology, 2012.

[5] D. P. Githa and W. E. Swastawan, "Parking System with Distance Visualization Using PING and LCD Sensors,"J. Nas. Educ. Tech. Inform., Vol. 3, No. 1, Pp. 1-5, 2014.

[6] R. Ramadi, "Making Travel History Travel GPS TRACKER Web Based on Mobile Phone Using J2ME," Informatics Engineering, Islam State University of Syarif Hidayatullah Jakarta, 2011.

[7] K. A. Gunawan, "As a Tool for Vegetable Seed Determinants," 2015.

[8] A. A. Dwitama, "Design and Implementation of RFID Based Parking System Using JAVA Interface And MySQL Database to be Implemented In FT UI Parking Environment," 2009.

[9] C. Nurdiyanto and T. Rahajoeningroem, "Designing Receiver Antennas in RFID Reader for Motor Vehicle Parking Application in Campus Environment UNIKOM," Vol. 4, No. 1, 2016.

[10] R. Dewi and L. Arianto, "Design of Electrical Space Control Systems Using Atmega 328 And Sms Gateway As An Information," Vol. 7, Pp. 1-10, 2015.

[11] M. Mujahidin, D. Nusyirwan, and M. Sc, "Prototype Design of Digital Indicators Based Petroleum Based Arduino UNO," 2013. 